\title{
PRECONCEITO E DISCRIMINAÇÃO ENTRE ALUNOS DO ENSINO MÉDIO
}

\author{
Lineu Norio Kohatsu ${ }^{1}$ \\ Leoncio Tavares Ferreira ${ }^{2}$ \\ Diana Ureña Acosta ${ }^{3}$ \\ Neusa Dayane Mendoza Patty ${ }^{4}$ \\ Júlia Demétrio Salgado 5
}

\begin{abstract}
Resumo: Neste artigo, são apresentados os resultados de uma pesquisa realizada no âmbito do Programa de Pré-Iniciação Científica da Universidade de São Paulo. A pesquisa teve por objetivo investigar as vivências e percepções de alunos de ensino médio sobre discriminação na escola e buscou comparar as respostas dos alunos de diferentes nacionalidades. A coleta de dados foi realizada em uma escola estadual no município de São Paulo, por meio de um questionário disponibilizado em formulário online, autopreenchido, além de entrevistas com dois alunos de origem boliviana. Constatou-se que as manifestações de discriminação na escola não são frequentes, sendo a xenofobia a forma mais mencionada pelos participantes. Foram constatadas também diferenças nas percepções de brasileiros/as, filhos/as de bolivianos e bolivianos/as.
\end{abstract}

Palavras-chave: Escola pública. Ensino médio. Imigrantes. Discriminação.

\section{Prejudice and discrimination among high school students}

Abstract: On this paper will be presented the results of a research made within the scope of the Scientific Pre-Initiation Program at the University of São Paulo. The objective of the research was to investigate the experience and perceptions of high school students about discrimination at school and sought to compare the responses of students of different nationalities. The data collect was made at a state school located at the city of São Paulo, through a questionnaire available in an online self-completed form, in addition, it was made interviews with two Bolivian students. It was found that the manifestations of discrimination at school are not frequent, with xenophobia being the most mentioned form by the participants. Differences were also found in the perceptions of Brazilian, children of Bolivian and Bolivian students.

Keywords: Public school. High school. Immigrants. Discrimination.

\footnotetext{
${ }^{1}$ Professor do Instituto de Psicologia da Universidade de São Paulo, pesquisador do Programa Ano Sabático do Instituto de Estudos Avançados - USP, pesquisador do Grupo Migrações e Identidades / CERU - USP.

${ }^{2}$ Professor Coordenador da Secretaria de Educação do Estado de São Paulo.

${ }^{3}$ Estudante de ensino médio, participante do Programa de Pré-Iniciação Científica da USP, bolsista CNPq.

${ }^{4}$ Estudante de ensino médio, participante do Programa de Pré-Iniciação Científica da USP, bolsista CNPq.

${ }^{5}$ Psicóloga, graduada pelo Instituto de Psicologia - USP.
} 


\section{Introdução}

Neste artigo são apresentados os resultados de uma pesquisa realizada no âmbito do Programa de Pré-Iniciação Científica da Universidade de São Paulo ${ }^{6}$.

A pesquisa foi conduzida por três alunas ${ }^{7}$ da $2^{\text {a }}$ série do ensino médio ${ }^{8}$, supervisionadas pelo coordenador pedagógico da escola e orientadas pelo professor do Instituto de Psicologia da USP - IP-USP, proponente do projeto ${ }^{9}$, tendo também a colaboração voluntária de uma aluna de graduação e pesquisadora de Iniciação Científica do IPUSP.

O projeto teve duração de um ano (2019-2020) e, nesse período, as alunas foram orientadas à busca de artigos sobre o tema em portais; seleção, leitura e discussão dos artigos mais relevantes; aprimoramento do projeto de pesquisa em relação aos objetivos e metodologia, elaboração dos instrumentos, coleta de dados, discussão dos resultados; elaboração do relatório de pesquisa e apresentação do trabalho no Simpósio Internacional de Iniciação Científica da USP.

O interesse pelo tema da discriminação surgiu das discussões sobre as vivências das alunas na escola, durante as reuniões com o professor supervisor e o professor orientador.

A relevância do tema se justifica pela presença crescente de filhos de imigrantes matriculados nas redes públicas de educação em São Paulo. Segundo dados obtidos junto à Secretaria Estadual da Educação, no ano de 2019, estavam matriculados na rede estadual de São Paulo 11.780 alunos estrangeiros, sendo $42 \%$ de nacionalidade boliviana (4.995 alunos). No ensino médio, constavam 2.923 matrículas de alunos estrangeiros, sendo 1.527 de bolivianos.

Embora o direito dos estudantes de origem estrangeira à educação escolar esteja previsto em lei, relatos dos próprios estudantes, profissionais das escolas e pesquisas acadêmicas apontam a existência de barreiras ao longo do processo de escolarização, principalmente decorrentes do preconceito e da discriminação. No entanto, ainda são poucas as pesquisas sobre o tema e mais raras ainda aquelas realizadas no contex to do ensino médio.

$\mathrm{Na}$ revisão de dissertações e teses brasileiras e portuguesas realizada por Kohatsu, Ramos, M. e Ramos, N. (2020), foram encontradas três pesquisas brasileiras que investigaram a relação entre estudantes brasileiros e de origem imigrante. Duas realizadas com alunos do ensino fundamental (OLIVEIRA, 2013; SOARES, 2015) e somente uma com estudantes do ensino médio (ROSA, 2016). Das três, apenas a de Oliveira (2013) investigou a situação de alunos de origem boliviana, apontando o isolamento e a submissão desses alunos, alvos de agressões verbais, físicas e tratamento pejorativo.

Em relação às pesquisas realizadas em Portugal, em três foram discutidas manifestações de preconceito e discriminação contra imigrantes. A pesquisa de Silva (2007) confirmou a hipótese da manifestação sutil de preconceito/racismo manifestada por estudantes

\footnotetext{
6Disponível em: https://www.ip.usp.br/site/apresentacao-pre-ic/.

${ }^{7}$ Participou também da pesquisa a aluna Beatriz Lins de Oliveira Martins, mas por razões pessoais não participou da elaboração do presente artigo.

${ }^{8}$ Agradecimentos ao CNPq pela concessão de bolsas de pesquisa às alunas participantes do Programa de PréIniciação Científica.

${ }^{9} \mathrm{O}$ projeto de Pré-Iniciação Científica é parte de um projeto guarda-chuva, de autoria do professor orientador.
} 
portugueses em relação aos colegas do Brasil, de Cabo Verde, da Ucrânia e da China. Botas (2010) analisou atitudes de crianças portuguesas em relação ao endogrupo e ao exogrupo (cabo-verdianos, brasileiros e chineses). Os resultados confirmaram a hipótese do favoritismo endogrupal com base na atribuição de mais adjetivos positivos autoatribuídos, não havendo, no entanto, depreciação do exogrupo. Todavia, a ausência de avaliação negativa não significa a ausência de preconceito, pois sua manifestação sutil é flagrada pela negação de traços positivos ao exogrupo. O estudo de Robalinho (2016) investigou as atitudes de jovens secundaristas portugueses em relação à imigração, cujos resultados apontaram atitudes positivas, sendo as raparigas mais favoráveis que os rapazes.

Ainda cabe menção de duas pesquisas que discutem a temática e não foram incluídas na revisão. A dissertação de Silva (2014), realizada na Unifesp, revelou preconceito e discriminação no modo como as educadoras de escolas de educação infantil se referiam às crianças de origem boliviana, sobre as dificuldades em relação à língua e à falta de higiene. Na tese de Oliveira (2019), publicada após a revisão, foi investigada a xenofobia e o racismo em escolas municipais de São Paulo.

Ademais, foi considerado um artigo que aborda a discriminação sofrida por estudantes imigrantes nas escolas. Miyahira e Sayar (2020) apresentam os resultados de uma pesquisa realizada em uma escola pública de São Paulo com estudantes do $8^{\circ}$ e $9^{\circ}$ anos do ensino fundamental, cujo objetivo foi analisar a relação entre estudantes bolivianos, filhos de bolivianos e brasileiros. Os pesquisadores não notaram situações de conflito ou perseguição aos alunos bolivianos, no entanto verificaram pouca interação entre os alunos de origem boliviana e os alunos brasileiros, inclusive separados na sala de aula.

Como se pode ver, ainda são raras as pesquisas que investigam as manifestações de preconceito e discriminação junto aos alunos do ensino médio, última etapa para conclusão da educação básica, conforme a Lei de Diretrizes e Bases da Educação Nacional Lei no 9394/96 (BRASIL, 1996), sendo este um dos níveis mais excludentes do sistema educacional brasileiro (SENKEVICS, CARVALHO, 2020). As barreiras são ainda mais desafiadoras para os estudantes imigrantes e suas famílias, que precisam superar vários obstáculos (documentação, aprendizagem da língua, invisibilidade social, preconceito, discriminação) para realizar o direito à educação (MAGALHÃES, SCHILLING, 2012).

A pesquisa apresentada neste artigo teve por objetivo principal investigar as vivências e as percepções de alunos/as de ensino médio sobre manifestações de discriminação na escola e buscou comparar as respostas de alunos/as brasileiros/as, brasileiros/as filhos/as de bolivianos e bolivianos/as às questões apresentadas em um questionário online autopreenchido. A proposta inicial era a aplicação nas salas de aula, mas devido à suspensão das atividades escolares presenciais por causa da pandemia da Covid-19, o procedimento teve de ser ajustado às condições dadas. Posteriormente, com o propósito de aprofundar a compreensão dos dados, foram realizadas também entrevistas semiestruturadas com dois alunos de família boliviana após o retorno parcial das atividades presenciais na escola. 


\section{Preconceito e discriminação: marcos legais e fundamentos teóricos}

Segundo o dicionário Aurélio (FERREIRA, 1999, p. 690), discriminação é o "ato ou efeito de discriminar; faculdade de distinguir ou discernir; separação, apartação, segregação: discriminação racial (...)".

Assim, embora a palavra discriminação não tenha apenas sentidos negativos, no cotidiano, é geralmente compreendida como ação que visa distinguir e diferenciar indivíduos ou grupos com base em características que apresentam (étnico-raciais, culturais, linguísticas, religiosas, de gênero etc.), que são interpretadas de modo a enfatizar uma conotação depreciativa, tendo como consequência a configuração de situações de desvantagem, produzindo impedimentos, segregação, perseguições e até genocídio.

A condenação da discriminação está presente na Declaração Universal dos Direitos Humanos (ORGANIZAÇÃO DAS NAÇÕES UNIDAS, 1948), nos artigos I, II e VII, em que se defende como princípio a igualdade humana, sem distinção de qualquer espécie e contrária a todas e quaisquer formas de discriminação

No Brasil, a Constituição Federal de 1988 estabelece no Artigo 5: "Todos são iguais perante a lei, sem distinção de qualquer natureza, garantindo-se aos brasileiros e aos estrangeiros residentes no País a inviolabilidade do direito à vida, à liberdade, à igualdade, à segurança e à propriedade (...), punindo qualquer discriminação, tornando a prática do racismo crime inafiançável e imprescritível”. A punição dos crimes de discriminação ou preconceito de raça, cor, etnia, religião ou procedência nacional foi ratificada pela Lei do Crime Racial, Lei no 7.716, de 5 de janeiro de 1989 (BRASIL, 1989). E ainda, a nova Lei de Migração $n^{\circ} 13.445 / 2017$ (BRASIL, 2017), tendo como fundamento a defesa dos direitos humanos, estabelece no Art. $3^{\circ}$, II - repúdio e prevenção à xenofobia, ao racismo e a quaisquer formas de discriminação.

A questão que se coloca é por que, mesmo perante a existência de normativas e dispositivos legais que condenam práticas discriminatórias, ainda persistem e se reproduzem as mais diversas formas de discriminação na sociedade e na escola? Com o intuito de compreender o preconceito, o racismo e a xenofobia, apresentamos uma breve discussão teórica a seguir.

Na pesquisa realizada por Crochík et al. (2013) sobre inclusão e discriminação escolar, foi realizada uma revisão teórica dos conceitos de discriminação, marginalização e segregação:

(...) segregação e marginalização como formas de discriminação social, e esta como ação derivada de preconceitos que a reproduzem; assim, sempre que há discriminação, existe preconceito, mas mesmo quando não há discriminação, pode haver preconceito (...) (CROCHÍK et al., 2013, p. 15).

Conforme Crochík (1997), o preconceito é uma atitude, uma predisposição, uma tendência, que pode resultar em ações como a discriminação. O preconceito se manifesta como opiniões subjetivas, crenças irracionais e convicções equivocadas acerca de certos objetos que não são baseadas em experiências reais. Diante da percepção distorcida da realidade, o indivíduo preconceituoso sente a necessidade de eliminar o que é percebido como hostil e ameaçador. No entanto, deve-se esclarecer que essas ameaças são imaginárias, mas 
mobilizam intensos afetos que não podem ser elaborados em virtude da postura defensiva e refratária à reflexão. Frequentemente, o indivíduo preconceituoso precisa se mostrar forte e dominador para ocultar o medo, a insegurança e a fragilidade que não pode admitir. Ademais, é incapaz de questionar o motivo pelo qual, mesmo se considerando superior, tem a necessidade de perseguir aqueles que percebe como mais fracos e inferiores, pois não pode admitir que a fragilidade de seu alvo é, na verdade, a própria fragilidade negada e projetada no outro.

Com base nos estudos realizados por T. W. Adorno et al. (2009) sobre a Personalidade Autoritária e nos estudos de Crochík (1997) sobre o preconceito, Kohatsu (2019) procurou demonstrar que a xenofobia como aversão ao estrangeiro é gerada pelo preconceito, assim como outras formas de discriminação, como o antissemitismo e o racismo.

Desse modo, sendo a xenofobia derivada do preconceito, ainda que o xenófobo tente encontrar algum argumento para justificar seus sentimentos intensos de medo e ódio em relação ao estrangeiro, sabemos que as razões dessa aversão são de natureza subjetiva, motivações psicológicas inconscientes. Portanto, sendo uma predisposição desfavorável, baseada em representações estereotipadas, convicções irracionais e emocionais inabaláveis sobre seus alvos, de pouco valerá tentar mostrar ao indivíduo xenófobo que os imigrantes não são os culpados pela crise econômica, pelo desemprego, pelo aumento da criminalidade, pelas doenças e pela difusão do terrorismo no mundo.

O imigrante - assim como o judeu, o negro, as pessoas LGBTQIA+ - é tomado como bode-expiatório por indivíduos preconceituosos, autoritários, antidemocráticos e fascistas para poderem canalizar a hostilidade e a agressividade que lhes são inerentes. Assim, se os alvos não existissem, precisariam ser inventados. Ainda que a perseguição pareça ser provocada e justificada pelas características de suas vítimas, por ser uma ação decorrente de uma necessidade psicológica do agressor, as particularidades dos indivíduos e grupos-alvo podem não ser tão relevantes, pois um indivíduo preconceituoso não será hostil somente com um determinado grupo minoritário, mas provavelmente expressará intolerância também em relação a outros grupos com características distintas, reduzidas à estereótipos.

Embora tais tendências sejam influenciadas por características psicológicas, deve-se recordar que o preconceito não é inato, tampouco um fenômeno estritamente individual, sendo gerado e reforçado pela cultura, cujos conteúdos são introjetados pelo indivíduo durante o processo de socialização, comprometendo a formação para a autonomia, inibindo o desenvolvimento do pensamento crítico, tornando-o suscetível aos movimentos regressivos de massa, como o fascismo.

A xenofobia, o antissemitismo, o racismo são ideologias, ou seja, são modos simplificados, estandardizados e mecanizados de organizar opiniões, atitudes e valores (ADORNO et al., 2009), usados para confirmar a inferioridade de certas minorias e justificar formas de discriminação, como a marginalização e a segregação, e ações de hostilidade e perseguições, tal como ocorreu na Alemanha nazista, na África do Sul e continuam ocorrendo em países como os Estados Unidos e o Brasil.

No espaço da escola são reproduzidos, em algum nível, atitudes e discursos preconceituosos e discriminatórios, pois esta não está apartada da sociedade. Assim, quanto menos democrático for o clima vigente na sociedade, maior será a probabilidade de relações autoritárias e antidemocráticas ocorrerem na escola. A escola, apesar de não poder manter a 
distância desejada em relação às tendências destrutivas dominantes na sociedade, pode, em alguma medida, desenvolver algum nível de autonomia em relação à totalidade social e exercer algum grau de resistência à reprodução da violência.

O enfrentamento da violência social que se reproduz na escola é uma tarefa hercúlea, não raras vezes sisífica, mas as consequências danosas aos alunos não permitem omissão diante do problema. Atualmente, a forma mais mencionada de violência na escola é o bullying, mas se sabe que não é a única, pois outras expressões de violência continuam recorrentes no cotidiano de muitas escolas públicas e particulares.

Pelo que se pode ver na revisão da literatura realizada por Crochík (2019), o bullying refere-se a comportamentos agressivos físicos e/ou verbais (ameaça, coerção, intimidação, insultos, humilhação, piadas) apresentados por um aluno mais forte ou um grupo de alunos contra alunos mais fracos, tímidos, isolados, inseguros, indefesos e que apresentam características físicas, como obesidade ou magreza, étnicas, de orientação sexual e/ou aparência que não são toleradas pelos agressores. Além do dano físico, os agressores visam a agressão psicológica que fragiliza ainda mais a capacidade de defesa das vítimas, tornando-as mais vulneráveis e reforçando a assimetria de poder. É importante recordar que a dificuldade de reagir à violência não é só da vítima, mas também daqueles que presenciam a agressão. Aliás, vale recordar que além da vítima e do agressor, outros papéis são exercidos no bullying, como os espectadores, que podem apoiar ou não a agressão.

A relação entre preconceito e bullying é concebida de modos distintos por pesquisadores que se fundamentam na teoria crítica. Antunes e Zuin (2008) criticam o modo como o conceito de bullying é usado, de modo instrumental e pragmático, ocultando o condicionamento social da violência. Para os autores:

O bullying se aproxima do conceito de preconceito, principalmente quando se reflete sobre os fatores sociais que determinam os grupos-alvo, e sobre os indicativos da função psíquica para aqueles considerados como agressores. (ANTUNES, ZUIN, 2008, p. 36).

Para Crochík (2015), no entanto, há diferenças entre o preconceito e o bullying que precisam ser consideradas. Em geral, o indivíduo preconceituoso tem seus alvos mais delimitados, relacionados às minorias sociais, com justificativas de perseguição mais específicas, associadas a estereótipos. No bullying, os alvos não são delimitados como no preconceito; as escolhas ocorrem mais em função da fragilidade das vítimas, e a agressão não precisa ser justificada.

Segundo Crochík "o bullying é uma expressão mais direta da violência estrutural da sociedade, mais arcaico e mais difícil de combater” (CROCHÍK, 2015, p. 41). Se no preconceito, os afetos indicam que há alguma identificação entre agressor e vítima, mesmo que essa tenha de ser negada, no bullying ocorre a negação da identificação, o que pode explicar a frieza ou ausência de afetos em relação à vítima. O bullying é uma forma de violência mais primitiva, mais imediata, correspondendo à regressão provocada da sociedade administrada.

As diferenças entre o preconceito e o bullying podem ser entendidas como resultantes do desenvolvimento da personalidade em diferentes momentos históricos, revelando a relação 
invertida entre a parte e o todo, ou seja, quanto mais desenvolvida a sociedade, menos desenvolvida será a personalidade:

(...) o bullying é uma forma de manifestação individual suscitada por uma sociedade bastante desenvolvida e traz consigo necessidades psíquicas menos desenvolvidas dos que as que se apresentam no indivíduo que tem o preconceito mais arraigado, indicando que, com as mudanças na estrutura da sociedade, caracterizada principalmente pela passagem do capitalismo mercantilista para o de monopólios, a estrutura da personalidade preconceituosa não somente se modifica, mas torna-se menos desenvolvida, como argumentam Horkheimer e Adorno (1947/1985), citados em Crochík $(2019$, p. 4)

A respeito de ações para enfrentamento do bullying nas escolas, duas pesquisas merecem ser citadas: uma realizada com diretores e coordenadores pedagógicos (CROCHÍK et al., 2014) e outra realizada com professores (SILVA et al., 2017), ambas feitas em escolas públicas e os resultados discutidos à luz da teoria crítica. Dessa forma, o ponto de partida para o entendimento do bullying é a relação entre totalidade e o particular, ou seja, a dimensão social é essencial à compreensão das manifestações particulares de violência. Entende-se que o fenômeno não se restringe às relações entre os indivíduos envolvidos, à família ou à instituição escolar, mas deve ser analisada a partir dos determinantes sociais mais gerais.

$\mathrm{Na}$ pesquisa realizada por Crochík et al. (2014) com diretores e coordenadores pedagógicos de cinco escolas públicas municipais de São Paulo, buscou-se responder duas perguntas: "Por que ocorre o bullying?" e "O que é necessário fazer para combatê-lo?" A análise dos dados obtidos mostrou que as "escolas que expuseram com mais precisão a determinação social sobre a violência escolar apresentaram propostas mais estruturadas de combate ao bullying" (CROCHÍK et al. 2014, p. 125), ou seja, envolvendo toda a escola, diferentemente daquelas que agiam de forma mais imediata, atuando unicamente sobre as relações entre indivíduos, agindo de modo pontual somente quando o problema aparece.

Silva et al. (2017) realizaram entrevistas com 17 professores, de cinco escolas públicas, perguntando o que produz o bullying e o que deve ser feito para reduzi-lo. Foram identificadas três categorias de respostas: 1) respostas que expressaram consciência crítica a respeito de sua produção e redução do bullying; 2) respostas que denotaram engajamento dos professores em relação ao combate ao bullying, mas consciência restrita sobre suas causas; 3) respostas que não apresentaram consciência a respeito da produção e do enfrentamento ao bullying. Os resultados apontaram semelhanças com a pesquisa realizada com os gestores, ou seja, as respostas que expressaram consciência crítica, considerando o entrelaçamento entre as dimensões individual, institucional e social se associavam a propostas mais consistentes para o enfrentamento. Por outro lado, visões mais restritas em relação aos fatores determinantes do bullying se relacionavam com propostas que reduziam o fenômeno a relações causais pouco articuladas com o contexto social e com a dimensão institucional. Os pesquisadores finalizam o estudo apontando a formação cultural dos professores como um dos elementos centrais na luta contra a barbárie. Por fim: "a esperança de que a escola, ao tomar consciência de que também propaga a barbárie a partir de si mesma, assuma o objetivo de desbarbarizar a humanidade" (SILVA et al., p. 54, 2017). 


\section{A pesquisa}

A pesquisa foi realizada em uma escola estadual de ensino fundamental e médio, situada no município de São Paulo.

Em 2019, ano do início do projeto, estavam matriculados aproximadamente 1.100 alunos, 311 no ensino médio e na Educação de Jovens e Adultos (EJA).

A escola é uma das unidades da rede estadual com mais alunos imigrantes e filhos de imigrantes, majoritariamente de origem boliviana.

A pesquisa foi conduzida, sob supervisão e orientação dos professores, por três alunas da $2^{\mathrm{a}}$ série do ensino médio da mesma escola onde foi realizada a investigação.

\section{Objetivos}

A pesquisa teve por objetivo principal investigar as vivências e as percepções de alunos de ensino médio sobre manifestações de discriminação na escola; quais as situações de discriminação mais relatadas e as reações e sentimentos provocados e comparar as respostas de alunos brasileiros/as, brasileiros/as filhos/as de bolivianos e bolivianos/as.

\section{Participantes}

Alunos/as do $9^{\circ}$ ano do ensino fundamental e alunos/as do ensino médio.

\section{Instrumentos}

1. Questionário disponibilizado em formulário online, autopreenchido, com 18 questões objetivas, sendo as sete primeiras sobre informações pessoais (idade, ano/série, nacionalidade, nacionalidade dos pais, gênero e religião) e 11 questões referentes às vivências de preconceito e discriminação na escola, elaboradas a partir das vivências das próprias pesquisadoras.

2. Roteiro de entrevista semiestruturada, elaborado com base nos itens do questionário.

\section{Procedimento de coleta de dados}

A proposta inicial era a aplicação do questionário nas salas de aula, mas devido à suspensão das atividades escolares presenciais por causa da pandemia da Covid-19, o procedimento teve de ser ajustado às condições disponíveis.

O convite aos alunos foi enviado aos respectivos pais e responsáveis, contatados pelo professor coordenador por meio de listas, solicitando para acessarem o questionário disponível no formulário online.

Posteriormente, com o propósito de aprofundar a compreensão dos dados, foram realizadas também entrevistas semiestruturadas com dois alunos de famílias bolivianas após o retorno parcial das atividades presenciais na escola. As entrevistas foram conduzidas pelas alunas pesquisadoras, realizadas presencialmente na escola, após o retorno das atividades 
presenciais autorizado pela Secretaria Estadual da Educação, seguindo todos os protocolos de segurança e higiene exigidos pela Vigilância Sanitária; a entrevista foi acompanhada remotamente pela pesquisadora voluntária de Iniciação Científica, aluna do curso de graduação do Instituto de Psicologia. A entrevista foi gravada após autorização dos pais e dos alunos.

\section{Procedimentos éticos}

O projeto de pesquisa desenvolvido pelas alunas faz parte do projeto de pesquisa do orientador, submetido e aprovado pelo Comitê de Ética do Instituto de Psicologia da Universidade de São Paulo (CAAE 61993016.7.0000.5561).

As informações sobre a pesquisa, os cuidados éticos, os dados e contatos das pesquisadoras e dos professores do Termo de Consentimento Livre e Esclarecido foram informados no formulário enviado aos pais. O questionário foi acessado somente pelos alunos cujos pais autorizaram a participação de forma anônima, sem exigência de identificação.

\section{Procedimentos de análise}

Os dados obtidos pelo questionário online foram sistematizados e comparados para responder às questões da pesquisa.

As entrevistas foram transcritas, as informações mais relevantes foram destacadas e posteriormente cotejadas com os dados obtidos pelo questionário.

\section{Resultados e discussão}

O questionário foi respondido por 58 alunos, sendo 34 brasileiros (18 masculinos, 14 femininos e 2 sem resposta); 19 brasileiros, filhos de bolivianos (7 masculinos e 12 femininos) e 5 bolivianos/as ( 2 masculinos e 3 femininos). A faixa etária variou de 14 a 19 anos; três participantes informaram idades muito acima da média, provavelmente a idade dos responsáveis.

Em relação ao ano/série, obtivemos números próximos de respostas: $9^{\circ}$ ano (11 respostas); $2^{\mathrm{a}}$ série do ensino médio (16 respostas); $3^{\mathrm{a}}$ série (15 respostas) e 16 participantes não informaram a série. A escola não tem turmas da $1^{\mathrm{a}}$ série do ensino médio em virtude da reorganização escolar.

A maioria dos participantes é de religião católica (30, sendo 17 brasileiros/as; 10 filhos/as de bolivianos e 3 bolivianos/as), seguida pela religião evangélica/cristã ( 9 , sendo 3 brasileiros; 5 filhos/as de bolivianos e 1 boliviano), budista (1 brasileiro), umbanda (2 brasileiras), Deus (1 brasileiro), cinco responderam Nenhum (4 brasileiros e um filho de boliviano) e 10 não responderam.

A questão "Com quem você não gostaria de namorar?" visava verificar se haveria manifestação explícita de rejeição a algum grupo étnico no que tange relações afetivas. Foram 
apresentadas as alternativas: branco, negro, asiático, indígena, não me importo com cor. A maioria, tanto dos/as brasileiros/as (33 respostas/100\% dos brasileiros), como dos filhos/as de bolivianos (19 respostas/ 95\% dos filhos de bolivianos) e dos/as bolivianos/as (3 respostas/75\% dos bolivianos) afirmou não se importar com a cor/etnia do/a parceiro/a. No entanto, três garotas explicitaram rejeição: uma que não revelou a raça/etnia contra negros, uma filha de bolivianos contra asiáticos e uma boliviana contra brancos. O resultado mostra que a maioria não considera a cor ou a origem étnica como impedimento para a escolha dos/as parceiros/as, indicando ausência de preconceito ou discriminação de modo explícito.

As questões seguintes foram agrupadas em três grandes blocos que visavam obter respostas sobre ter presenciado alguma situação de preconceito/discriminação na escola; ter discriminado e ter sofrido discriminação.

\section{Bloco 1 - "Você já presenciou alguma situação de preconceito/discriminação na escola?"}

Este bloco foi formado por quatro questões: 1) se já presenciou alguma situação de preconceito/discriminação na escola; 2) qual tipo; 3) como se sentiu e 4) como reagiu.

A maioria (48 respostas/82,8\%) respondeu que presenciou situação de preconceito/discriminação alguma vez na escola. A opção mais assinalada foi "Às vezes" (20 respostas/35,4\%), seguida por "Muitas vezes" (17 respostas/29,3\%), "Nunca" (10 respostas/17,2\%) e "Sempre" (8 respostas/13,8\%).

Proporcionalmente, os/as filhos/as de bolivianos (masculino 100\%; feminino 83,3\%) e os/as bolivianos/as (masculino e feminino 100\%) presenciaram situações de preconceito/discriminação com mais frequência do que brasileiro/as (masculino 66,7\%; feminino 85,7\%). O grupo "brasileiros" (masculino) foi o que apresentou menor frequência.

Apenas 10 participantes ( 8 brasileiros/as e 2 filhas de bolivianos) responderam que "nunca" presenciaram.

A questão sobre o tipo de discriminação presenciada permitia ao participante assinalar mais de uma opção.

A xenofobia foi a forma de preconceito/discriminação mais assinalada (26 respostas); proporcionalmente mais mencionada por filhos/as de bolivianos $(52,6 \%)$ e também pelos bolivianos/as $(80 \%)$ do que por brasileiros/as $(33,3 \%)$, provavelmente porque é a situação que mais lhes afeta.

O preconceito/discriminação de gênero/orientação sexual foi a segunda mais mencionada (24 respostas), a maioria por brasileiros/as (17 respostas); rapazes de origem boliviana não assinalaram esse tipo de preconceito/discriminação, mas todas as garotas bolivianas assinalaram. Um/a do/as brasileiros/as que não identificou gênero respondeu que presenciou preconceito/discriminação relacionada à gênero/orientação sexual. A recusa à identificação de gênero pode estar relacionada com a vivência de discriminação.

O preconceito/discriminação racial (18 respostas) foi a terceira mais citada, seguida por preconceito/discriminação de classe social (17 respostas) e a gordofobia (16 respostas). Esta última é a única não relacionada a grupos minoritários, mas às características pessoais, que são visadas por praticantes de bullying (Crochík, 2015).

Seis rapazes brasileiros não responderam e uma garota brasileira, filha de bolivianos, também não. 
Duas garotas tinham assinalado na questão anterior que nunca presenciaram situação de preconceito/discriminação na escola, mas responderam afirmativamente nesta questão.

Na questão "Como se sentiu?", a alternativa mais mencionada foi "Indignado" (32 respostas/64\%), assinalada tanto por brasileiros/as (22 respostas), como por filhos/as de bolivianos (7 respostas) e bolivianos (3 respostas).

"Triste" (9 respostas) foi assinalada por 3 brasileiros/a; 4 filhos/as de bolivianos e 2 bolivianos/as.

A soma das respostas "Indignado" (32 respostas) e "Triste" (9 respostas) indica que a maioria dos participantes $(70,7 \%)$ reprova as manifestações de preconceito/discriminação. A única resposta "Surpreso" pode indicar que tais manifestações não são esperadas e não deveriam ocorrer.

No entanto, chamou a nossa atenção a resposta "Indiferente" assinalada por uma brasileira, pela/o a/o participante brasileira/o que não assinalou gênero e quatro descendentes de bolivianos. Esse tipo de resposta levanta a suspeita de pouca empatia diante do sofrimento dos pares. A opção "Engraçado" assinalada por uma brasileira e uma filha de bolivianos pode indicar que essas pessoas, como espectadoras, podem encontrar diversão nessa prática. Em ambas as situações, parece não haver identificação com aquele que é vitimizado; a gravidade da violência não é percebida ou negada, sendo tomada como brincadeira, sem que se consiga avaliar as consequências negativas da agressão, principalmente se for recorrente.

$\mathrm{Na}$ questão "Como você reagiu?", as alternativas "Só olhei" (24 respostas/48\%) e "Defendi a vítima" (24 respostas/48\%) foram as mais mencionadas. "Fingi que não vi" foi assinalada por filhos de bolivianos (2 respostas). "Ajudei a zoar" não foi assinalada.

"Só olhei" e "Fingi que não vi" podem ter diferentes sentidos, como indiferença, cumplicidade com o agressor ou impotência do espectador diante de uma situação de violência. $\mathrm{O}$ desafio parece perpassar em dar voz e escuta para que esses jovens se sintam potentes para atuar diante dessa situação.

Em contrapartida, a opção "Defendi a vítima", assinalada por 24 participantes, mostra que muitos não conseguem atuar para interromper esta situação de violência. Nessa opção, chama atenção que, dos que assinalaram que defenderam a vítima, encontramos uma diferença grande entre brasileiros e bolivianos ou filhos de bolivianos. Enquanto 53,8\% (14 respostas) dos brasileiros defenderam a vítima, apenas 36,8\% (7 respostas) dos filhos de bolivianos assinalaram essa mesma opção. Enquanto isso, dos 4 bolivianos, 3 assinalaram essa alternativa. Essa diferença pode dizer respeito ao processo xenofóbico estruturado em nossa sociedade, que inferioriza grupos e dificulta que esses grupos se sintam potentes para atuar.

Oito participantes não responderam essa questão (7 brasileiros/as e uma filha de bolivianos).

\section{Bloco 2 -"Você já discriminou alguém na escola?"}

Dos 58 participantes, 55 responderam e a maioria assinalou que "Nunca" discriminou (37 respostas/67,3\%). Em dois grupos - filhas de bolivianos e bolivianas - nenhuma participante assinalou já ter discriminado. 
A opção "Uma vez" foi assinalada por brasileiros/as (6 respostas/20\% dos brasileiros), um filho de bolivianos e um boliviano. Cinco brasileiros e dois filhos de bolivianos assinalaram "Às vezes".

Somente um/a brasileiro/a (que não identificou gênero) assinalou "Muitas vezes". Ninguém assinalou "Sempre", dando a entender que no grupo de participantes não havia agressor recorrente.

Considerando as respostas por nacionalidade, 12 brasileiros/as discriminaram alguma vez; três filhos de bolivianos e um boliviano discriminaram alguma vez. Desse modo, proporcionalmente, mais brasileiros $(33,3 \%)$ discriminaram alguma vez, quase o dobro do grupo filhos/as de bolivianos e bolivianos $(17,4 \%)$.

Analisando as respostas por gênero, os participantes do gênero masculino assinalaram 10 respostas e as do gênero feminino quatro respostas. Proporcionalmente, a discriminação ocorreu mais entre os rapazes $(37,0 \%)$ do que em relação às garotas $(13,8 \%)$.

$\mathrm{Na}$ pergunta subsequente, foi perguntado como era a pessoa discriminada. Os tipos mais assinalados foram "Gorda" (6 respostas); "Negro, indígena, asiático" (4 respostas); "LGBTQI+" (3 respostas); "Pobre" (2 respostas); "Imigrante" (2 respostas); 41 não responderam. O resultado mostra coerência, pois 37 participantes responderam na questão anterior que "Nunca" discriminaram. No entanto, quatro participantes que assinalaram que "Nunca" discriminaram, responderam esta questão.

Embora "Xenofobia" tenha comparecido como a opção mais assinalada em outra questão, entre os participantes, pelo que vimos, apenas dois assinalaram terem discriminado "Imigrantes". A opção "Gorda" foi a mais assinalada como alvo de discriminação dos participantes.

Na pergunta "Por que você fez isso?", a opção mais assinalada foi "Foi mal, pediria desculpas" (7 respostas); seguida por "Todos fazem" (3 respostas); "Ela mereceu" (3 respostas); "Foi zoeira" (2 respostas); 44 não responderam, número maior do que o esperado (37 respostas), que assinalaram "Nunca" discriminaram. A maioria dos participantes mostrou arrependimento por ter cometido preconceito/discriminação, contudo chama atenção que oito justificaram o ato.

\section{Bloco 3 -"Você já sofreu discriminação na escola?"}

As opções para esta questão foram: "Nunca" (6 respostas); "Uma vez" (5); "Às vezes" (11); "Muitas vezes" (7); "Sempre" (0); 29 não responderam, a maioria de brasileiros/as (14 masculinos; 12 femininos; 2 sem indicação de gênero). Pelo que se vê, a alternativa mais assinalada foi “Às vezes”, indicando que, mesmo tendo sofrido preconceito/discriminação, não foi algo frequente. Podemos inferir que pela baixa frequência tais atos não se caracterizavam como bullying.

Considerando as respostas que indicaram alguma ocorrência, ao analisarmos por nacionalidade, verificamos que os/as brasileiros/as sofreram menos preconceito/discriminação (4 respostas/11,8\%) do que os/as filhos/as de bolivianos (15 respostas/78,9\%) e bolivianos/as (4 respostas/80,0\%). Foram os filhos/as de bolivianos (4 respostas) que mais sofreram "Muitas vezes". 
O sentimento mais frequente provocado pela discriminação foi a tristeza (19 respostas); seguido por "Levei na brincadeira" (9 respostas); "Bravo" (8 respostas); "Indignado" (8 respostas); "Surpreso" (2 respostas); 12 não responderam.

Uma aluna boliviana e uma filha de boliviana responderam nunca terem sofrido discriminação na escola, mas nesta questão assinalaram ter se sentido "triste", indicando incoerência entre as respostas.

A última questão do bloco e do questionário perguntava "Como você reagiu?" à discriminação.

Por ordem decrescente: “"Me defendi" (24 respostas/ 51,1\%)); "Quieto" (17 respostas/ 36,2\%); "Denunciei” (3 respostas/ 6,4\%); "Outros" (3 respostas/ 6,4\%); a opção "Agredi” não foi assinalada; 11 não responderam.

A postura mais ativa diante do preconceito/discriminação foi apresentada pelos brasileiros/as; das 24 respostas "Me defendi", 15 foram de brasileiros (masculino 9 respostas; feminino 6 respostas); "Denunciei” (masculino 2 respostas).

Das 17 respostas à opção "Quieto", 11 foram assinaladas pelos/as filhos/as de bolivianos (masculino 2 respostas; feminino 8 respostas) e boliviana (1 resposta); as filhas de bolivianos foram as que apresentaram maior passividade diante da agressão. Este resultado contribuiria para reforçar o estereótipo de passividade dos alunos de origem boliviana, mas deve-se considerar que "Me defendi" foi a segunda opção mais assinalada (9 respostas, 5 por filhos/as de bolivianos e 4 por bolivianos/as).

Nenhum participante respondeu "Agredi" como reação à discriminação sofrida. Todavia, a resposta "Denunciei" teve frequência baixa, indicando que procurar alguma forma de ajuda institucional não foi considerada uma alternativa diante da discriminação.

\section{Entrevistas}

Para complementar os dados obtidos pelo questionário, foram realizadas duas entrevistas semiestruturadas. Seguem abaixo, os resumos das entrevistas.

\section{Jonathan}

Jonathan ${ }^{10}, 16$ anos, brasileiro, filho de pais bolivianos, cristão e estava na $2^{\mathrm{a}}$ série do ensino médio na ocasião da entrevista.

Em relação ao namoro, disse que não tem preferência (inferimos que se referia à raça/etnia e classe social), tal como a maioria dos participantes assinalou no questionário. Contou que namorou com duas garotas e ao ser indagado se eram brasileiras respondeu que eram de famílias bolivianas. Em outro trecho da entrevista, quando lhe é perguntado se namoraria uma garota "japonesa", respondeu que não teria problemas e que os pais aceitariam. Desse modo, se ele e a sua família não fazem objeção à etnia, a dificuldade em namorar com uma brasileira estaria na aceitação por parte da garota: "É meio difícil, né? Por você ser boliviano."

\footnotetext{
10 Seguindo os procedimentos éticos, os nomes dos entrevistados foram substituídos para preservar suas identidades.
} 
Sobre os amigos, responde que são brasileiros e bolivianos, mas diante da insistência reconhece que tem mais amigos de origem boliviana.

Sobre preconceito e discriminação, disse que nunca sofreu, mas já presenciou quando estava no $8^{\circ}$ ano: "Eu já presenciei. Tinha um boliviano menor... boliviano do $6^{\circ}$ ano, os meninos do $7^{\circ}$ foram pra cima dele. O menino era um pouquinho baixinho e era gordinho." Jonathan conta que se sentiu "abalado" e tentou conversar, mas foi ignorado pelos agressores, que continuaram insultando o aluno menor. Segundo Jonathan, os insultos ocorriam devido à aparência desse aluno, que era baixo e gordo. E complementa dizendo ter tentado conversar com o grupo de brasileiros agressores, mas não teve sucesso:

A situação foi no intervalo. Tava na cantina... "boliviano gordinho" começaram a zuar a aparência dele... Vamos conversar com esses caras. Dois brasileiros que xingaram ele. Nós fomos conversar com eles, a gente conversou... "não se mete onde você não é chamado". A gente conversou e eles continuaram. Não pararam. Ele é boliviano, sinto muito.

Jonathan representa a minoria que nunca sofreu discriminação. No entanto, como a maioria dos participantes, conta que já presenciou uma situação na escola. $\mathrm{O}$ caso relatado ilustra as respostas obtidas pelo questionário. Por um lado, a vítima se porta de modo passivo, sem reação diante dos agressores que são maiores e mais velhos, mas Jonathan ao presenciar a situação, tem como reação sentir-se "abalado" e tenta intervir, mas sem conseguir dissuadir os agressores. Nenhum deles, a vítima ou Jonathan, buscaram ajuda ou denunciaram a situação, tal como nas respostas obtidas pelo questionário.

Destacamos também que a discriminação é influenciada pelas características da vítima, de origem boliviana, e também por ser "gordinho", conforme a descrição de Jonathan. Os dados obtidos pelo questionário apontam que a xenofobia é a forma mais frequente de discriminação, conforme os participantes, sendo a gordofobia a terceira mais citada, juntamente à discriminação racial.

A entrevista concedida por Jonathan aponta a existência de duas formas de discriminação: uma mais sutil, por se sentir preterido pelas brasileiras; outra, mais brutal, quando os agressores explicitam, sem pudores, o motivo da perseguição: "Ele é boliviano, sinto muito" - dando a entender que a agressão é legitimada pelas características do alvo, sendo totalmente refratários à tentativa de argumentação apresentada por Jonathan.

\section{Milenka}

Milenka, 18 anos, boliviana, católica, filha de pais bolivianos, veio ao Brasil com oito anos de idade. Estudou na Bolívia até a $3^{\text {a }}$ série. No Brasil estudou o ensino fundamental na Escola $\mathrm{E}$ e frequenta a $2^{\mathrm{a}}$ série do ensino médio na Escola A.

Disse que não se importaria com características de raça/etnia, mas nunca namorou pessoas de outra etnia e atualmente namora um rapaz brasileiro, de família boliviana. Conta que a maioria dos amigos também é de descendência boliviana.

Disse que nunca viveu situação de discriminação nas escolas brasileiras, mas presenciou situação de gordofobia. Preferiu não falar mais sobre isso, mas disse ter se sentido mal, com vontade de fazer algo, mas acabou não interferindo. Em outro momento da 
entrevista, quando novamente lhe perguntaram sobre a situação de discriminação presenciada, voltou a repetir que não fez nada: "Eu não fiz nada, só vi." Comenta que não é de falar muito, mas em outro momento da entrevista relata que fala bastante com pessoas conhecidas, com quem tem mais intimidade, como a colega $\mathrm{N}$.

Quando eu comecei a conhecer ela, eu era muito quieta, aí foi mais me relacionando com ela, começou a ser mais liberal, fui me soltando mais, falando mais com ela." (...) Peguei intimidade com ela e falei mais. Agora, em outras situações, eu sou mais na minha mesmo.

Apesar do esforço das entrevistadoras, Milenka não desenvolveu muito as respostas, geralmente curtas e objetivas. Talvez a dificuldade seja decorrente do cansaço, pelo fato de ter trabalhado a noite toda na feira da madrugada.

Assim como Jonathan e a maioria dos participantes do questionário, Milenka não vê problemas em namorar uma pessoa de outra etnia. No entanto, namorou e namora uma pessoa de família boliviana.

O relato de Milenka também vai ao encontro dos dados obtidos por meio do questionário. Embora diga que nunca sofreu discriminação, conta que já presenciou e não conseguiu reagir, tal como muitos que responderam ao questionário. Na situação mencionada, a discriminação foi motivada por gordofobia, mas não foi possível saber se a vítima também era de origem boliviana, como no relato de Jonathan.

\section{Discriminação e preconceito na escola: enfim, o que fazer?}

Com base nos dados obtidos pelo questionário e pelas entrevistas, é possível constatar que na escola em questão ocorrem manifestações de preconceito e discriminação, mas com pouca frequência.

Pelas respostas obtidas, a maioria dos participantes se mostra contrária ao preconceito/discriminação, não apresentando rejeição explícita a qualquer grupo étnico para namoro. Ademais, demonstra indignação ao presenciar tais manifestações e apresenta tentativa de agir em defesa da vítima. Entre os poucos que assinalaram já ter discriminado, a maioria demonstra arrependimento e pediria desculpas.

Além disso, cabe destacar as diferenças entre brasileiros/as, filhos/as de bolivianos e bolivianos observadas nas respostas, tal como apontadas anteriormente. A partir disso, decorre que potenciais alvos de preconceito e discriminação são mais sensíveis à percepção da violência do que aqueles que não o são.

Os resultados obtidos sugerem que o preconceito/discriminação explícitos não são tão frequentes, no entanto permanecem de modo encoberto, velado; não como rejeição aberta, mas como não preferência, como percebido pelos entrevistados, o que pode resultar em separação ou pouca interação positiva entre brasileiros e imigrantes, como também observou Miyahira e Sayar (2020).

A manifestação sutil, não explícita ou velada, contribui para reforçar o argumento daqueles que negam a existência do preconceito e da discriminação, dificultando o enfrentamento e contribuindo para a perpetuação da violência no interior da escola. 
Entende-se, em concordância com Crochík (2019), que a violência que se manifesta na escola é em grande parte gerada pela totalidade social. Assim, não estando apartada da sociedade, a escola sozinha não pode solucionar o problema sem que mudanças estruturais sejam realizadas. Isso não significa, no entanto, que não há nada a ser feito pela escola para reduzir a violência em seu interior. Pelo contrário, pelos danos psicológicos provocados às vítimas, que afetam não só a escolarização, mas também outros âmbitos da vida, alguma ação da escola se torna necessária e urgente. Contudo, as ações não devem ser imediatistas e pontuais para "apagar incêndios", pois essas servem, na melhor das hipóteses, como paliativos temporários e pouco eficazes.

Assim como mostraram os estudos de Crochík et al. (2014) e Silva et al. (2017), é necessário investir em políticas públicas que estimulem a formação crítica dos educadores e gestores, no sentido de proporcionar a compreensão dos fatores sociais que geram a violência, mas, e principalmente, que haja compromisso político e apoio institucional à autonomia do coletivo escolar para a elaboração e implementação de planos de ação mais consistentes, duradouros e efetivos para o enfrentamento da violência.

Segundo Adorno (1995), o objetivo principal da educação é que Auschwitz não se repita - a afirmação segue atual e verdadeira. A violência precisa ser freada para que a civilização não seja totalmente destruída. Se o argumento não servir aos que defendem a educação apenas para o aumento do capital, talvez seja necessário avisar que a escola que não assumir como prioridade o enfrentamento da violência, jamais será uma escola produtiva.

\section{Referências Bibliográficas}

ADORNO, T. W. Educação após Auschwitz. Educação e emancipação, v. 3, p. 119-138, 1995.

ADORNO, T. W. et al. Estúdios sobre la personalidad autoritária. In: ADORNO, T. W. Escritos Sociológicos II: Obra Completa. Madrid: Ediciones Akal, 2009. p. 145-187.

ANTUNES, D. C.; ZUIN, A. A. S. Do bullying ao preconceito: os desafios da barbárie à educação. Psicologia e Sociedade, v. 20, n. 1, p. 33-41, jan./abr. 2008.

BOTAS, S. C. C. Atitudes de crianças em relação aos grupos nacionais. 2010. Dissertação (Mestrado em Relações Interculturais) - Universidade Aberta, Lisboa, 2010.

BRASIL. Constituição da República Federativa do Brasil. São Paulo: Saraiva, 1998.

BRASIL. Lei $n^{o} 7.716 / 1989$, de 5 de janeiro de 1989. Define os crimes resultantes de preconceito de raça ou de cor. Brasília: Diário Oficial da União, 1989.

BRASIL. Lei $n^{o}$ 9394/1996, de 20 de dezembro de 1996. Estabelece as diretrizes e bases da educação nacional. Brasília: Diário Oficial da União, 1996.

BRASIL. Lei $n^{\circ}$ 13.445/2017, de 24 de maio de 2017. Institui a Lei de Migração. Brasília: Diário Oficial da União, 2017. 
CROCHÍK, J. L. Formas de violência escolar: preconceito e bullying. Movimento, v. 2, n. 3, p. 29-56, 2015.

- Preconceito e bullying: marcas da regressão psíquica socialmente induzida. Psicologia USP, v. 30, p. 1-11, 2019.

. Preconceito, indivíduo e cultura. São Paulo: Robe editorial, 1997.

CROCHÍK, J. L. et al. Análise de concepções e propostas de gestores escolares sobre o bullying. Acta Scientiarum Education, v. 36, n. 1, p. 105-113, fev. 2014.

. Inclusão e discriminação na educação escolar. Campinas: Alínea, 2013.

FERREIRA, A. B. H. Novo Aurélio: o dicionário da língua portuguesa: século XXI. Rio de Janeiro: Nova Fronteira, 1999.

KOHATSU, L. N. Imigração, assimilação e xenofobia: algumas notas. Cadernos CERU Dossiê Migrações, v. 30, n.1, p. 50-75, 2019. Disponível em: http://www.revistas.usp.br/ceru/article/view/158699. Acesso em: 01 dez. 2020.

KOHATSU, L. N.; RAMOS, M. C. P.; RAMOS, N. A educação escolar de alunos imigrantes em dissertações e teses brasileiras e portuguesas: o desafio da inclusão das diferenças. In: PEREIRA, R. M. C., LIMA, S. P., SANTOS, Z. G. C. (Orgs.). Geopedagogia: a escola em mapas mentais de estudantes brasileiros, bolivianos e haitianos. Porto Velho: EDUFRO, 2020. p. 149-175.

MAGAlHÃES, G. M.; SCHILlinG, F. Imigrantes da Bolívia na escola em São Paulo: fronteiras do direito à educação. Pro-Posições, v. 23, n. 1, p. 43-64, abr. 2012.

MIYAHIRA, E.; SAYAR, K. R. Interculturalidade na escola pública de São Paulo. Cadernos CERU, v. 31, n. 1, p. 250-267, 2020.

OLIVEIRA, L. M. Imigrantes, xenofobia e racismo: uma análise de conflitos em escolas municipais de São Paulo. 2019. Tese (Doutorado em Educação) - Pontifícia Universidade Católica de São Paulo, São Paulo, 2019.

OLIVEIRA, L. R. P. Encontros e confrontos na escola: um estudo sobre as relações sociais entre alunos brasileiros e bolivianos em São Paulo. 2013. Dissertação (Mestrado em Educação) - Pontifícia Universidade Católica de São Paulo, São Paulo, 2013.

ORGANIZAÇÃO DAS NAÇÕES UNIDAS. Declaração Universal dos Direitos Humanos. ONU, 1948.

ROBALINHO, T. F. D. Atitudes em relação à imigração: um estudo com jovens estudantes do ensino secundário. 2016. Dissertação (Mestrado em Psicologia) - Universidade do Porto, Portugal, 2016.

ROSA, E. S. et al. A inserção de alunos imigrantes africanos negros na rede estadual de ensino na cidade de São Paulo (2014-2016). 2016. Dissertação (Mestrado em Educação) Pontifícia Universidade Católica de São Paulo, São Paulo, 2016. 
SENKEVICS, A. S.; CARVALHO, M. P. Novas e velhas barreiras à escolarização da juventude. Estudos Avançados, v. 34, n. 99, p. 333-352, ago. 2020.

SILVA, A. P. No hablamos español! Crianças bolivianas na educação infantil paulistana. 2014. Dissertação (Mestrado) - Escola de Filosofia, Letras e Ciências Humanas, Universidade Federal de São Paulo, Guarulhos, 2014.

SILVA, C. I. S. Preconceitos etnoculturais: meio rural e meio urbano - contributo para a educação intercultural. 2007. Dissertação (Mestrado em Relações Interculturais) Universidade Aberta, Lisboa, 2007.

SILVA, P. F. et al. Limites da consciência de professores a respeito dos processos de produção e redução do bullying. Psicologia USP, v. 28, n. 1, p. 44-56, abr. 2017.

SOARES, C. F. Imigrantes e nacionais: um estudo sobre as relações sociais em sala de aula. 2015. Dissertação (Mestrado em Educação) - Pontifícia Universidade Católica de São Paulo, São Paulo, 2015. 